\title{
Natural hydrogen resource potential of Australia
}

\section{CHRISTOPHER J BOREHAM}

\author{
Geoscience Australia
}

Presenting Author: Chris.Boreham@ga.gov.au

The inferred resource potential of molecular hydrogen $\left(\mathrm{H}_{2}\right)$ in Australia has been assessed as world class (Moretti et al., 2021). However, such an assessment is based on indirect, untested methodologies and the presence of only a handful of $\mathrm{H}_{2}$-rich natural gases $\left(\mathrm{H}_{2}>10 \mathrm{~mol} \%\right)$ (Boreham et al., 2021). The identification of abiogenic $\mathrm{H}_{2}$-rich gases associated with gold mineralisation in the Neoarchean Yilgarn Craton, Western Australia has extended prospective areas to structures not traditional targeted by petroleum exploration drilling (ibid).

Models of $\mathrm{H}_{2}$ production rates based on water radiolysis mediated by the radioactive decay of $\mathrm{U}$, Th and K-bearing minerals, coupled with helium production rates ( $\alpha$-particles from $\mathrm{U}$ and Th decay), can apportion water radiolysis and mineral hydration redox reactions (e.g. ferrous-ferric iron in serpentinization). However, data limitations and extrapolations at local-global scales can result in a wide range in calculated minimum and maximum $\mathrm{H}_{2}$ production rates (ibid).

Using the data in Wilford and Kroll (2019), radiogenic U, Th and $\mathrm{K}$ contents and rock densities are assigned at a $100 \mathrm{~m} \times 100 \mathrm{~m}$ grid spacing across onshore Australia. The modelled $\mathrm{H}_{2}$ production rate is a minimum of $\sim 1.6 \mathrm{MMm}^{3} \mathrm{yr}^{-1}$ to a depth of 1 $\mathrm{km}$. This compares with a maximum rate of $\sim 58 \mathrm{MMm}^{3} \mathrm{yr}^{-1}$ for Australia's share from global Precambrian cratons. Although the reasons for such a wide range in $\mathrm{H}_{2}$ production rate estimates are not fully understood, the current analysis provides the foundation for continued re-assessment with new knowledge and datasets of Australia's natural $\mathrm{H}_{2}$ resource potential.

References:

Boreham, C.J., Sohn, J.H., Cox, N., Williams, J., Hong, Z. and Kendrick, M.A., 2021. Hydrogen and hydrocarbons associated with the Neoarchean Frog's Leg Gold Camp, Yilgarn Craton, Western Australia. Chemical Geology. Hydrogen and hydrocarbons associated with the Neoarchean Frog's Leg Gold. In press. https://doi.org/10.1016/j.chemgeo.2021.120098

Moretti, I., Brouilly, E., Loiseau, K., Prinzhofer, A. and Deville, E., 2021. Hydrogen emanations in intracratonic areas: new guidelines for early exploration basin screening. Geosciences 11(3), 145. https://doi.org/10.3390/geosciences 11030145

Wilford, J. R., and Kroll, A., 2019. Complete radiometric grid of Australia (Radmap) v4 2019 with modelled infill. Geoscience Australia, Canberra. http://pid.geoscience.gov.au/dataset/ga/144413 